\title{
Research on Model of Resource Management for Grid Based on Viral Marketing
}

\author{
Xin-Juan Zhao ${ }^{1, \text { a }}$, Ya-Lin Chen ${ }^{1, \text { b }}$ and Ji-Yi Zhao ${ }^{2, c}$ \\ ${ }^{1}$ Network Education \& Administration Center, Henan University of Technology, Zhengzhou 450001, \\ China \\ ${ }^{2}$ Research and Development Department of Market, Pingyuan Industry Filter Co.,LTD, Xinxiang \\ 453000, China \\ a zhao_xinjuan@163.com, b chenyalin@haut.edu.cn, ${ }^{\mathrm{c}}$ zhaojiyi3206@sina.com
}

\begin{abstract}
Keywords: Grid computing; Computational economy; Viral marketing; Opinion leader; Social network analysis; Data mining
\end{abstract}

\begin{abstract}
In Grid, resources are distributed, autonomous, heterogeneous and dynamical, and resource management and scheduling algorithms based on computational economy are very fit for solving problems of resource management for Grid. This paper introduces viral marketing into the model of resource management for Grid based on computational economy. The model of opinion leader mining is applied to the management of customer relationship, and the specific target groups are attracted through analysis. By the basic idea of social network analysis and the technology of data mining, valuable information is spread on a larger scale so that actions of users form resonances and diffuse in the model of resource management for Grid based on viral marketing. In addition, search time of information is reduced for customers. The model of resource management for Grid based on viral marketing has certain academic significance.
\end{abstract}

\section{Introduction}

In grid, there are all kinds of resources, which are dynamic, distributed and heterogeneous. These resources own enormous and specific customers. Decision-making of buying sometimes depends on informal information spread between people. So, oral spreading has more influence and persuasion [1]. The market mechanisms of economics theory are effective methods of resource management for grid, and offer efficient, extensible and steady mechanism. The paper introduces opinion leader of consumers into resource management for grid. The best of all resource services is chosen from available resources so that consumers are attracted to automatically request services and offered timely, quality services through viral marketing.

\section{Grid Computing}

Grid computing [2, 3] has emerged for solving problems of large-scale science computing. Grid is service-oriented systems and applications in the distributed computing. In other words, Grid provides various services. Grid collects and manages scattered heterogeneous resources and can realize efficient resource sharing and management through resource management model. Grid eliminates the information island and realizes the share of information resources. In addition, Grid has efficient, real-time, accurate abilities of cooperation and can provide the on-demand usage of resources and increase the interoperability of service infrastructure at a lower cost.

In a commercial on-demand grid, users and providers of resources can frequently come and go. The resource management is the most important to Grid. Grid can satisfy resource requesters' quality of service requirements. The core of grid is the share and cooperation of resources.

Computational economy. In grid, service providers and customers look forward to the maximization of anticipation. In order to satisfy allocation and regulation of supply and need for resources, this paper adopts several technologies. Game theory [4] is introduced into grid market, meanwhile, 
computational economy [5] regulates needs for grid resources. When resources are short, owners of resources are stimulated to join into traffic grid in order to seek maximal profit. Customers make use of resources economically. As grid resources are dealing, trade mechanism of game will be adopted to optimize goals of participants. Economical models with competition provide algorithms and strategies for share and distribution of resources in grid.

Viral marketing. Viral marketing [6] is first brought forward by Steve Jurvetson and Tim Draper in 1997. They think that everyone can be promulgator of information in Internet. The attention of people is rare resources. The key of internet marketing is how to attract the attention of consumers.

American famous electron business adviser, R. F. Wilson, thinks viral marketing stimulates the transmission of marketing information and the exponential increase of consumer's numbers [7].

Viral marketing depends on enthusiasm and relational network of consumers and continuously stimulates impressionable crowd. Marketing information automatically transmits and spreads like real viruses. Marketing information is rapidly replicated and transferred to millions of consumers. The way of marketing transmission is the application of Six Degrees of Separation (SDS). During publicizing products, viral marketing induces customers to make choices of same products.

Opinion leader. Opinion leader [8] earliest appears in the 1940's, which is first brought forward by Lazarsfeld, the pioneer of American famous Communication. Lazarsfeld discovers that information and opinion transmitted by media will be accepted by some audience and be transmitted again. Theses audience is opinion leader. Others conduct their deeds through touching with opinion leader. Rogers, American communication scholar, points out that interpersonal relationship and opinion leader are the central informal tunnel of information, in which the consuming infection goes on [9]. Information from media first arrives at opinion leader and is diffused to other colleague or followers by opinion leader. The process is called two-step flow of communication.

\section{Model of Resource Management for Grid Based on Viral Marketing}

Based on the merit of mobile agent, agent and viral marketing, this paper puts forward the model of resource management for Grid based on viral marketing. The model consists of various components displayed as follows (see Fig. 1).

Based on the basic thoughts of social network analysis [10] and data mining, model of mining opinion leader can find opinion leader by analyzing relational database of communication. Opinion leader in Grid market guides and has impacts on consumption behavior. Meanwhile, pertinence and services are improved. Information can be rapidly diffused in specific areas, which facilitates resources to be shared and used. With agglomeration effect of opinion leader, precise audience can be found and asymmetry of information can be reduced when consumers are choosing. So, information search time can be saved. Consumers can find what they want promptly.

Dynamic information of resources will be registered in Directory Service. Status information of resources will be stored in local directory servers as far as possible. Consumers such as mobile agent scan get effective information of resources they need.

Network weather service [11] is a distributed system, which monitors performance resource sensor and collect transient information. Network weather service might use monitoring information data as inputs for a prediction model, which would in turn be used by cooperation decision monitor to determine which resource to be used. Study mechanism of artificial intelligence is introduced into mathematical model so that the accuracy of performance forecast can be improved. Network weather service can infer trends of resource information on the base of dynamic information existed.

Grid bank is a distributed bank system. Parties of dealing have individual electronic accounts. As a party of dealing accessed one service, its account will be regulated. Grid bank performs statistics, account and the payment of electronic currency. Like bank system in reality, grid bank maintains owners' account consistency.

Grid market is an environment in which service providers compete. In Grid market, resources are categorized into static or dynamic resources. Based on economic principles, resource trading takes place. Grid market provides infrastructure for the management and dealing of resource. Through 
mechanism or policy provided by grid market, users have access to various resources belonging to different individuals or organizations. Resource price is set by resource needs and game models. The offer of buyer and seller is regulated dynamically. The profitability level is automatically regulated during negotiation of both dealing parties. Blind competition can be avoided with the help of powerful analysis of game theory.

Cooperation filter decision monitor is a monitor agent, which is responsible for global control of resource distribution. Besides, cooperation filter decision monitor mediates resources on the basis of optimal resource selection mechanism. Cooperation filter decision monitor runs task allocation algorithm. Cooperation task algorithm assigns tasks to suitable resources. Furthermore, cooperation filter decision monitor platform settles dynamic load balance of services and optimizes adaptive management of resource scheduling according to adaptive performance-based task allocation algorithm.

Resource recommending repository stores the recommendation results that cooperation filter decision monitor platform produces. Cache mechanism ensures recommendation results can be produced efficiently and quickly.

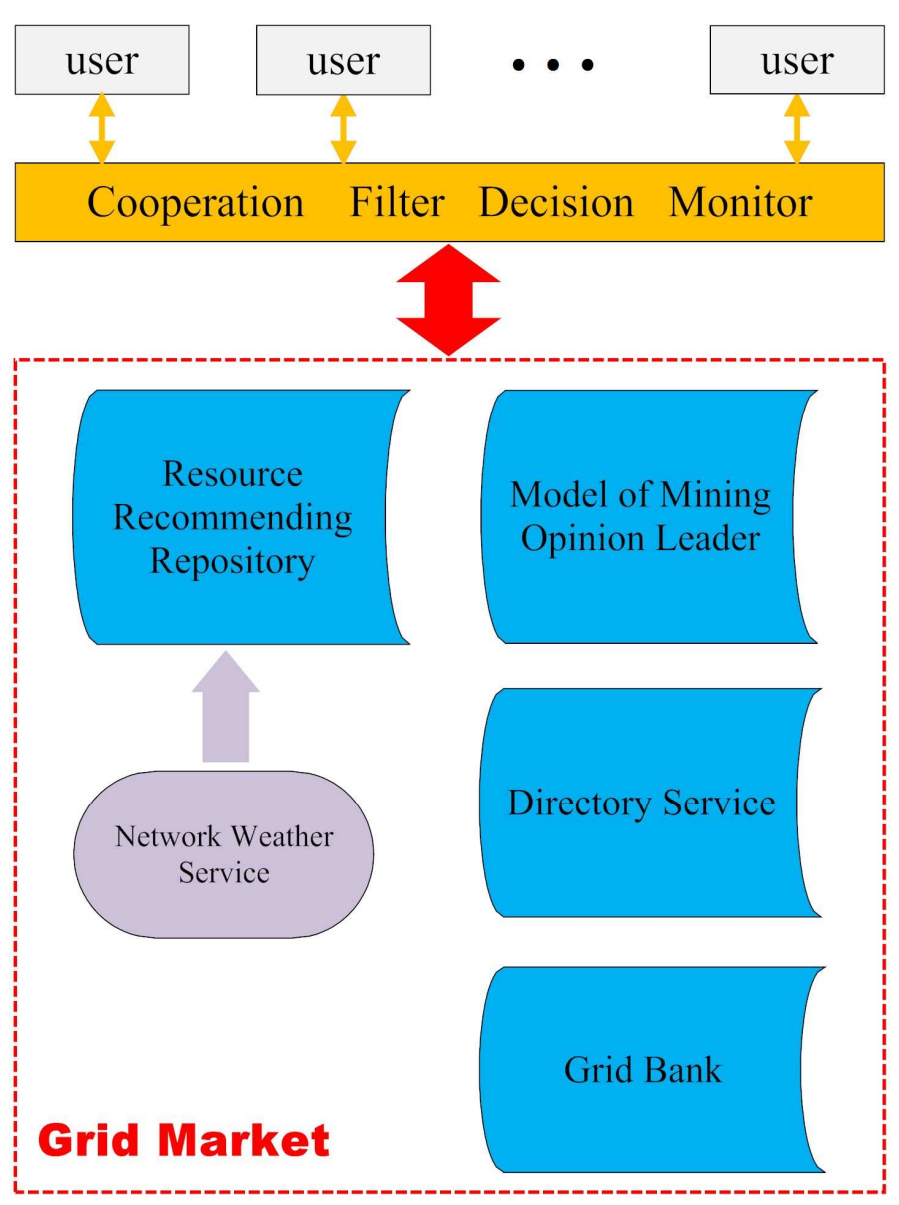

Fig. 1. Model of resource management for Grid based on viral marketing

\section{Summary}

Viral marketing, social network analysis, dada mining, mobile agent and agent are introduced into resource management for Grid based on viral marketing, which can realize Reasonable management of resources, dynamic load balance, resource effective sharing. Resource use rate can be improved. The goal of service providers and consumers can be optimized largely. Besides, qualities of service for consumers can be realized. 


\section{References}

[1] J.M. Bristor, Enhanced Explanations of Word of Mouth Communications: The Power of Relationships, Res. Consum. Behav. 4 (1990) 51-83.

[2] I. Foster, C. Kesselman, Computational Grids: The Future of High-Performance Distributed Computing, Morgan Kaufmann Publishers, 1998.

[3] I. Foster, C. Kesselman, and S. Tuecke, The anatomy of the grid: Enabling scalable virtual organization, Int. J. Supercomput. App. 15 (2001) 200-22.

[4] R. Gibbons, A Primer in Game, Harvester Wheasheaf, New York, 1992.

[5] D. Abramson, R. Buyya and J. Giddy, A Computational Economy for Grid Computing and its Implementation in the Nimrod-G Resource Broker, Future Gener. Comp. Sy. 18 (2002) 1061-1074.

[6] S. Jurvetson and T. Draper, Viral Marketing, the Netscape M-Files, 1997.

[7] R.F. Wilson, The Six Simple Principles of Viral Marketing, Web Market Today, 70 (2000) 1-3.

[8] E. Katz and P.F. Lazarsfeld, Personal Influence, The Free Press, Illinois, 1955.

[9] E.M. Rogers, Diffusion of Innovation, The Free Press, New York, 1995.

[10]S. Staab, P. Domingos, P. Mike, J. Golbeck, D. Li, T. Finin, A. Joshi, A. Nowak, R.R. Vallacher, Social networks applied, IEEE Intell. Syst. App. 20 (2005) 80-93.

[11]R. Wolski, N. Spring and J. Hayes. The Network Weather Service: A Distributed Resource Performance Forecasting Service for Metacomputing, Future Gener. Comp. Sy. 15 (1999) 757-68. 